\title{
Operational Concept for the NASA Constellation Program's Ares I Crew Launch Vehicle
}

Joel Best

Dr. Greg Chavers

Lea Richardson

Craig Cruzen

Engineering Directorate NASA Marshall Space Flight Center May 15, 2008

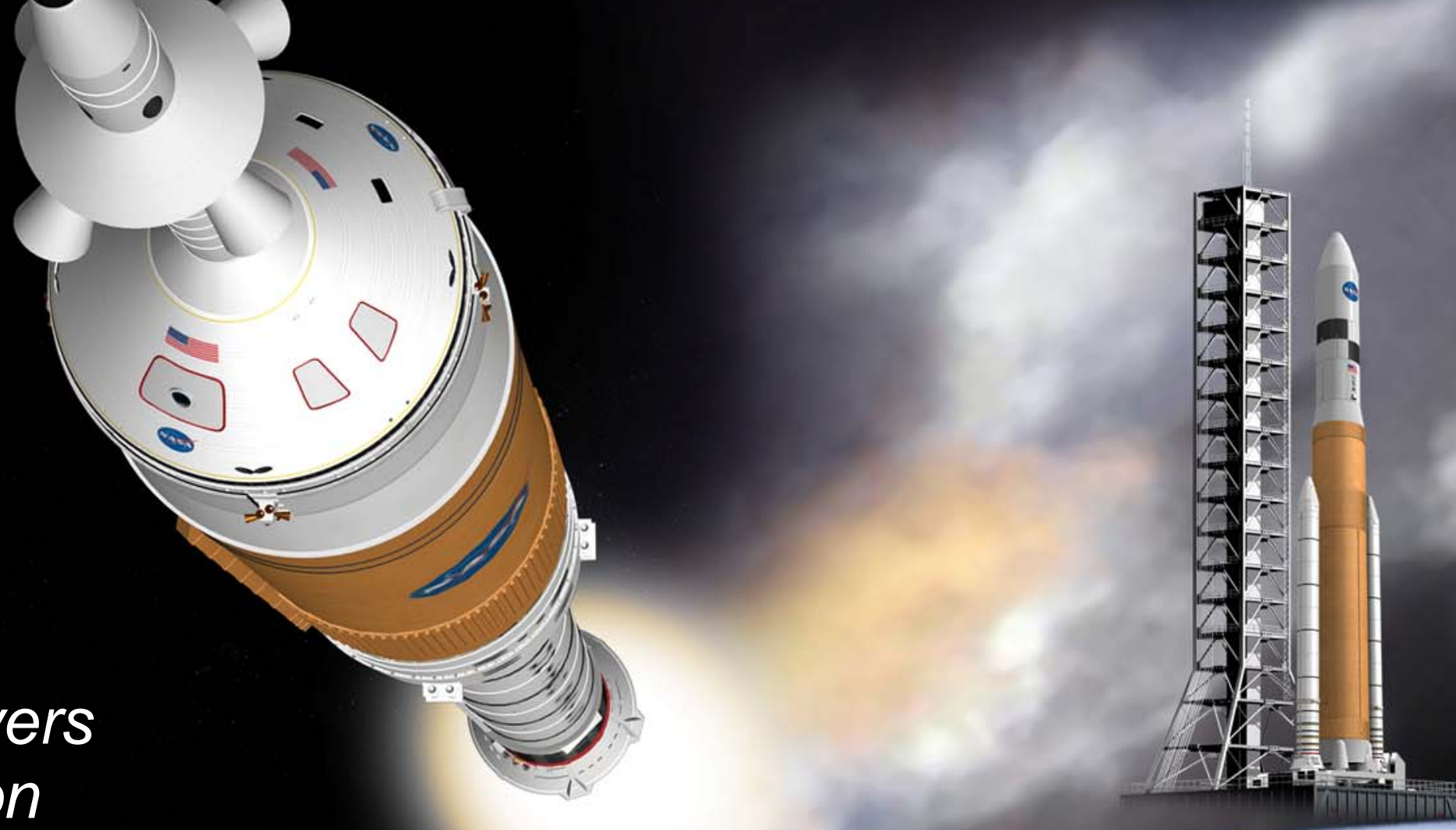




\section{Agenda}

$\checkmark$ Building on a Foundation of Proven Technologies

$\checkmark$ Ares I Elements

$\checkmark$ Orion Crew Exploration Vehicle

$\checkmark$ Ares V Elements

$\checkmark$ Key Ares I Operational Requirements

Overall Ares I Operational Flow

Example of Key Driving Requirement

$\checkmark$ Operational Concept

$\checkmark$ Summary 


\section{Ares I Elements}

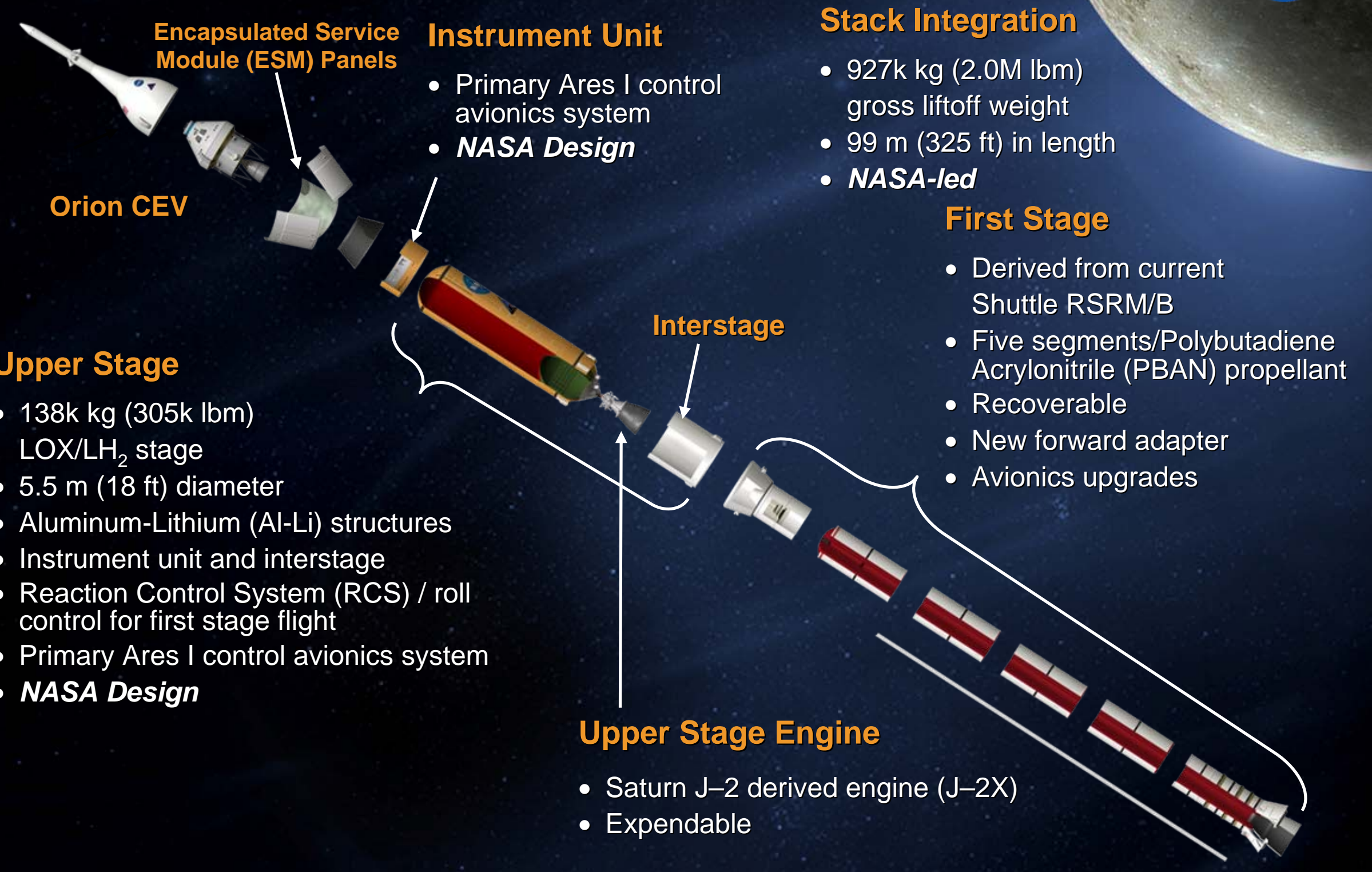




\section{Orion Crew Exploration Vehicle}

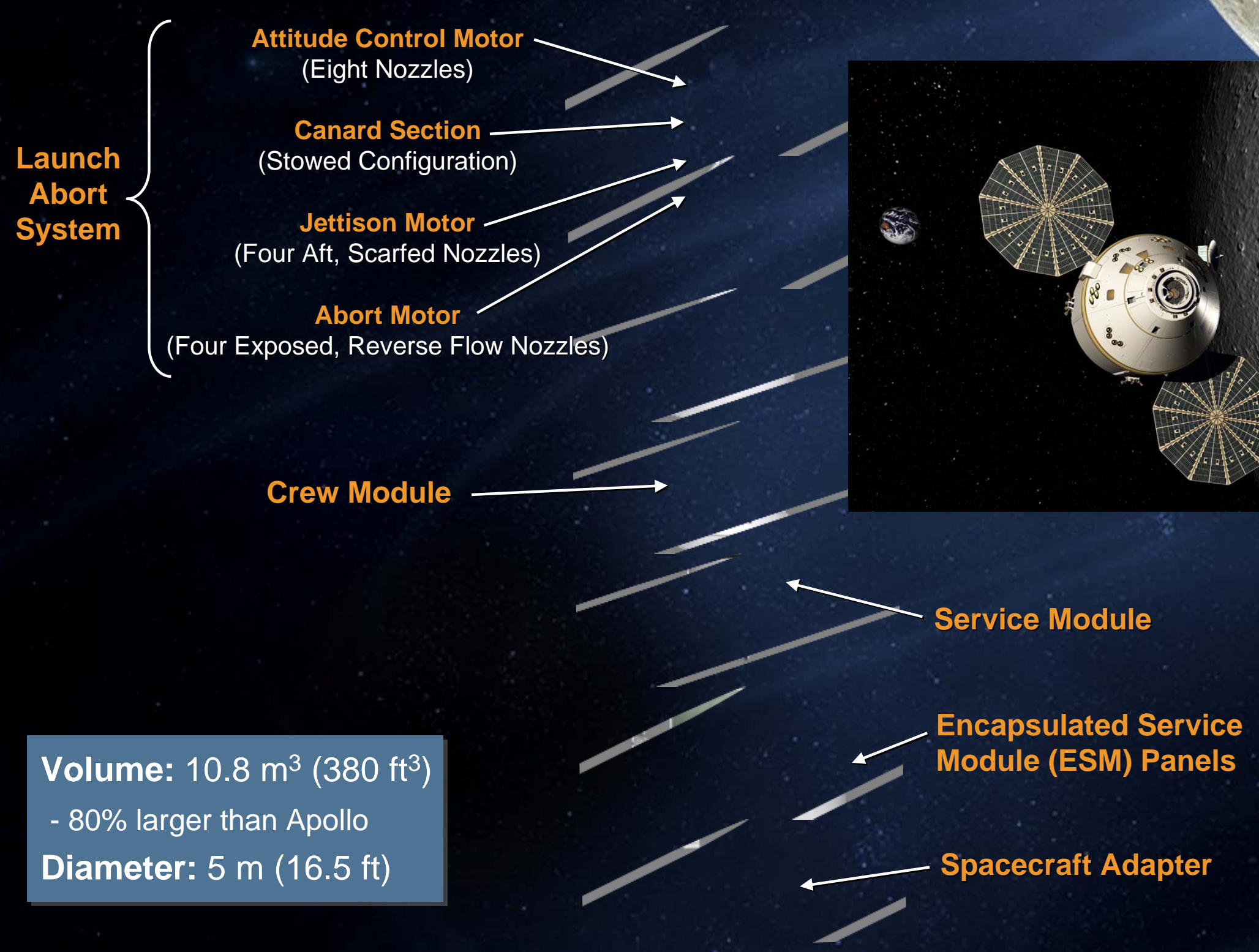




\section{Ares V Elements}

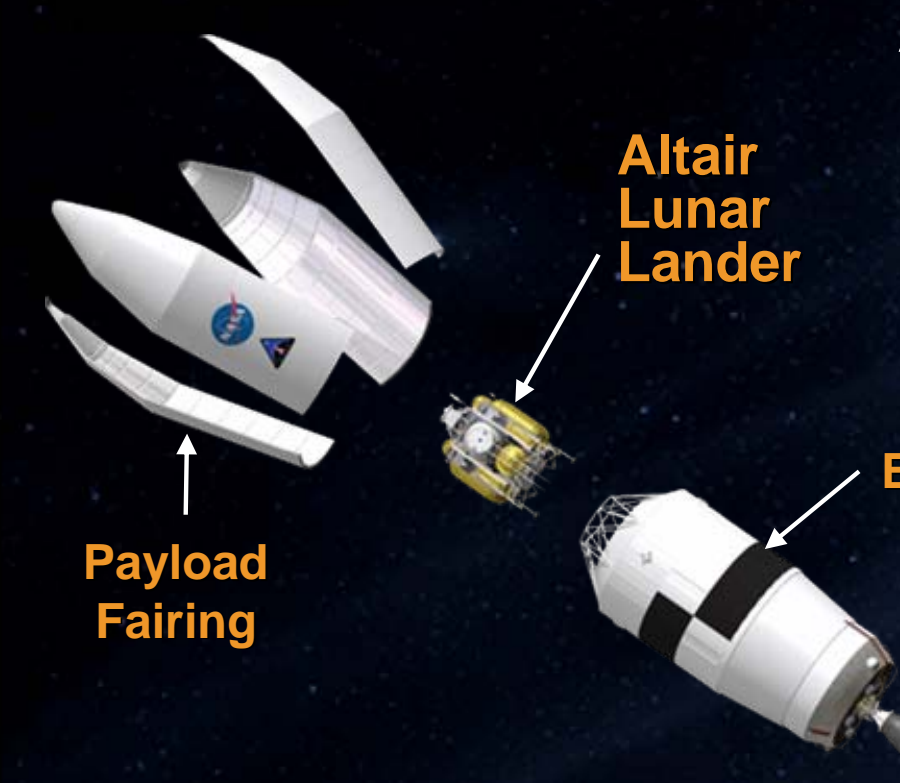

\section{Earth Departure Stage (EDS)}

- One Saturn-derived J-2X LOX/LH ${ }_{2}$ engine (expendable)

- $10 \mathrm{~m}$ (33 ft) diameter stage

- Aluminum-Lithium (Al-Li) tanks

- Composite structures

- Instrument unit and interstage

- Primary Ares V avionics system

\section{Stack Integration}

- $3.4 \mathrm{M} \mathrm{kg} \mathrm{(7.4M} \mathrm{lbm)} \mathrm{gross}$ liftoff weight

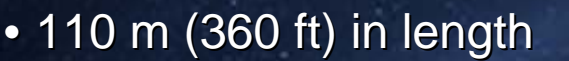
EDS

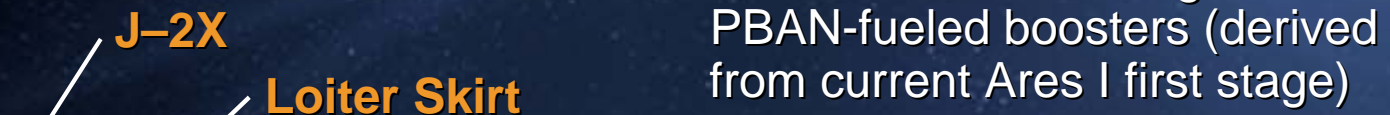

\section{First Stage}

- Two recoverable 5-segment PBAN-fueled boosters (derived current Ares I first stage)

\section{Core Stage}

- Five Delta IV-derived RS-68 LOX/LH ${ }_{2}$ engines (expendable)

- $10 \mathrm{~m}$ (33 ft) diameter stage 


\section{Key Ares I Operational Requirements}

$\checkmark$ Processed, integrated, and launched within 45 days.

- Capable of 6 launches per year.

s Interchangeable between International Space Station and Lunar missions.

Launch probability not less than $95 \%$ due to natural environments and monthly weather conditions, during the period beginning with the decision to load cryogenic propellants and ending with the close of the day-oflaunch window for the initial planned attempt.

- Probability of launching, beginning with decision to load cryogenic propellants, of not than $\mathbf{9 8 \%}$ (excluding weather).

$\rightarrow$ Minimize launch pad processing time such that the Ares I is ready for launch within 7 days from arrival at the launch pad.

- Capable of a 24-hour turnaround following a launch scrub for a minimum of 7 consecutive days to support the 7-day lunar launch window. 


\section{Overall Ares I Operational Flow}

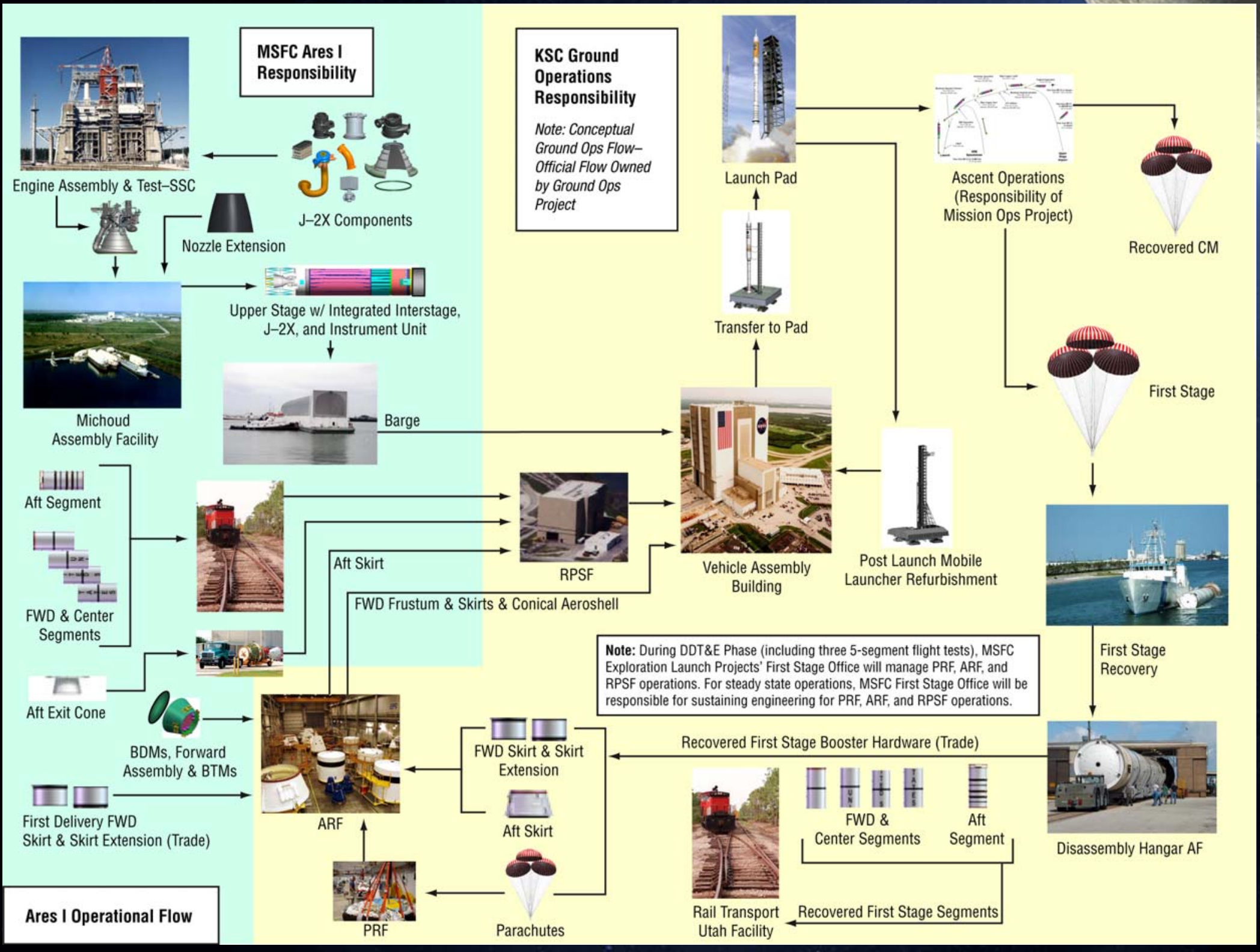




\section{Example of Key Driving Requirement Consecutive Launch Attempts for Ares [is}

- Ares I must tank for each Ares $V$ launch attempt, plus for each of lits own attempts after a successful Ares V launch, leading to a potential for 7 consecutive tankings of the Ares I before the missed Trans-Lunar Injection (TLI) window.

- Goal is to maximize launch attempts for TLI opportunity.

\section{4 consecutive Ares $V$ attempts}
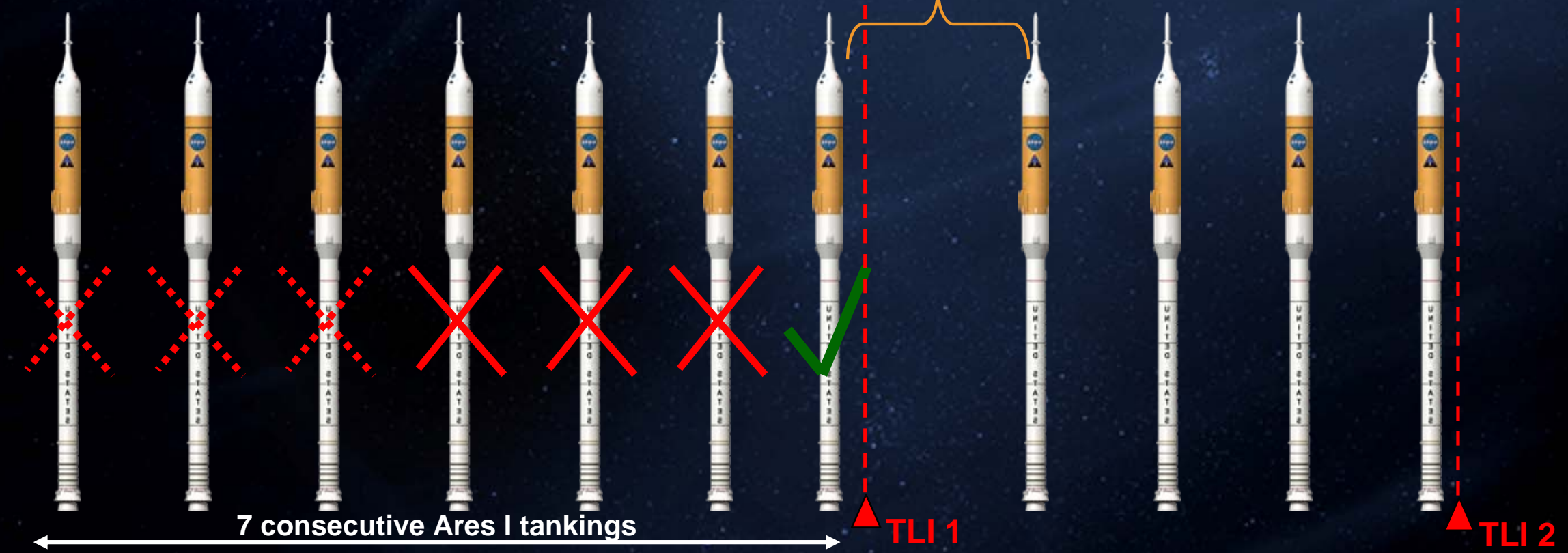


\section{Operational Concept:}

\section{Communications and Tracking Capability}

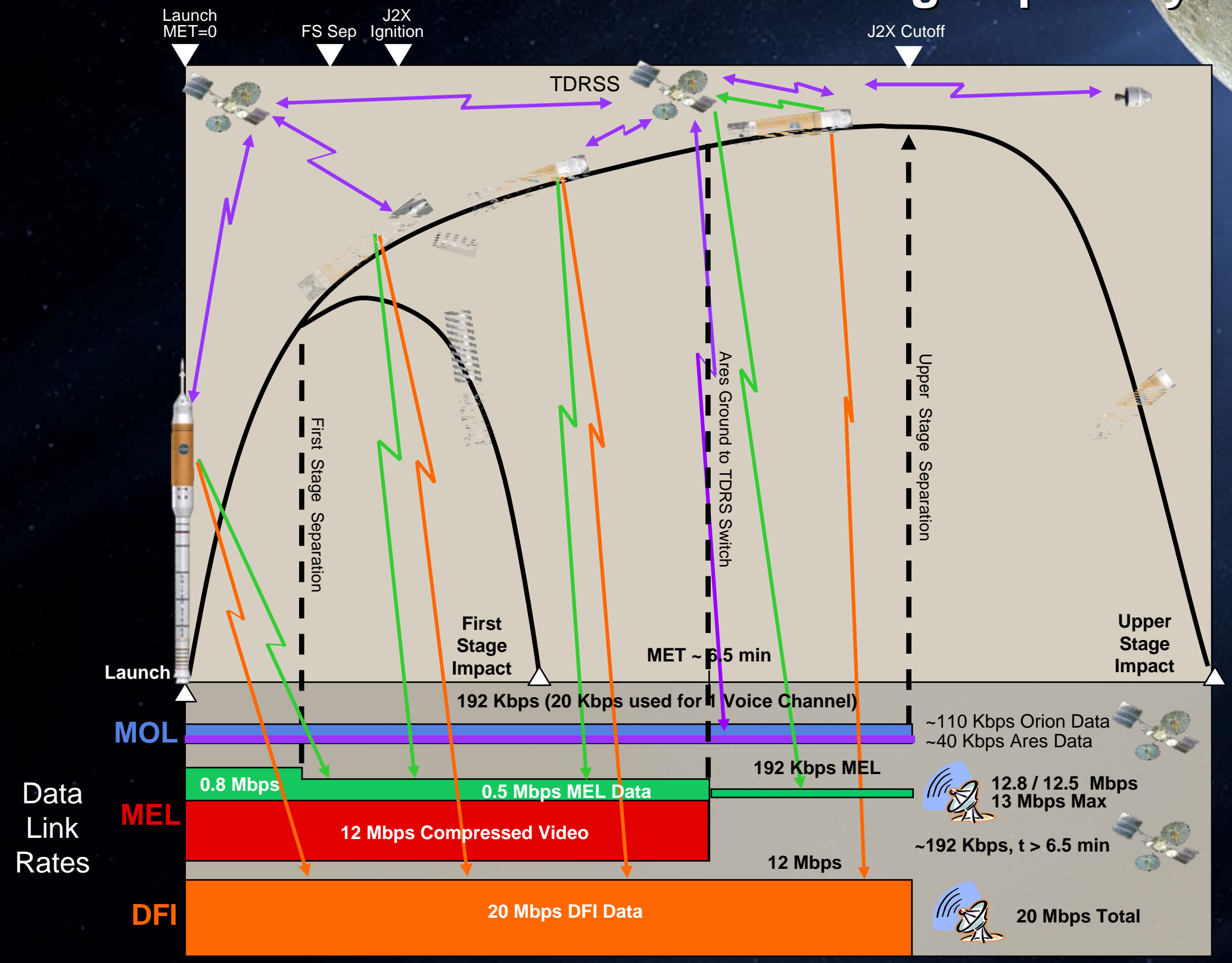




\section{Summary}

- Ares I design brings together innovation and new technologies with established infrastructure and proven heritage hardware to achieve safe, reliable, and affordable human access to space.

$\checkmark$ NASA has $\mathbf{5 0}$ years of experience from Apollo and Space Shuttle.

- The Marshall Space Flight Center's Mission Operations Laboratory is leading an operability benchmarking effort to compile operations and supportability lessons learned from large launch vehicle systems, both domestically and internationally.

- Ares V will be maturing as the Shuttle is retired and the Ares I design enters the production phase.

- More details on the Ares I and Ares V will be presented at SpaceOps 2010 in Huntsville, Alabama, U.S.A., April 2010. 


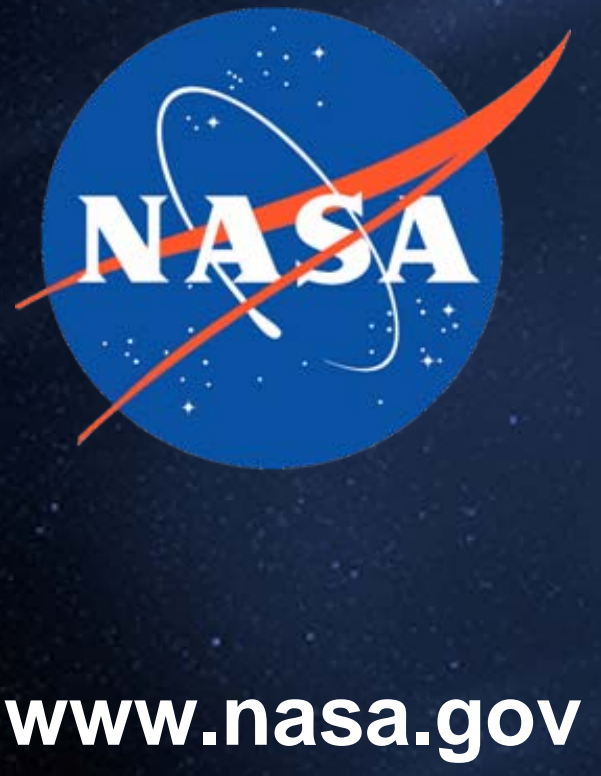

